\title{
RESPONSABILIDAD DEL ESTADO \\ COLOMBIANO EN EL MARCO DEL \\ DERECHO FUNDAMENTAL AL TERRITORIO \\ ANCESTRAL Y EL ACCESO A LA JUSTICIA INTERAMERICANA
}

Fernando Aurelio Guerrero Cárdenas

Abogado, Esp. Derecho Administrativo, Universidad Santo Tomás-Bucaramanga (Col). Asesor Jurídico para el Área de DD.HH y DIH, Comisión de Derechos Humanos y Audiencias del Senado República de Colombia.

E-mail:fernandoguerreroc@hotmail.com

\section{Resumen}

El siguiente artículo aborda la problemática de los territorios indígenas en Colombia a partir de los conflictos sociales y políticos que ha permeado las áreas rurales del país. El tema central es la posesión de tierras indígenas y su consecutivo despojo por terratenientes locales aliados con grupos al margen de la ley, frente a la responsabilidad del Estado colombiano por la poca legislación sobre el tema y la omisión al consultar a los pueblos indígenas sobre temas que competen a sus territorios. Los autores hacen un acercamiento desde la doctrina y la jurisprudencia al concepto de territorio ancestral, para elaborar un análisis de lo que implica otorgar el estatus de territorio indígena, finalmente hacen un llamado de atención al lector a proteger y garantizar los derechos colectivos de las comunidades dentro de sus territorios ancestrales y la posibilidad de materializar dichas garantías accediendo al sistema interamericano.

\section{Palabras clave}

Territorios ancestrales, posesión de tierras indígenas, Responsabilidad administrativa, derechos fundamentales y colectivos de pueblos indígenas y Sistema Interamericano

\begin{abstract}
The following article approaches the problem around aboriginal territories in Colombia because the social and political conflicts have extended to the rural areas of the country. The main topic is the possession of the territory by aboriginal people and the constant use of illegal force by local landowners allied with criminal groups to dispose them of their land and the responsibility of the Colombian state due to poor legislation about the subject and the omission to consult aboriginal communities about the topics that concern their territories. The authors make an approach to the concept of ancestral land from the doctrine and jurisprudence, to elaborate an analysis that implies the right to establish an aboriginal territory status. Finally, they appeal to the attention of the reader to protect and guarantee the collective rights of the aboriginal communities within their ancestral territories and the possibility of materializing those guarantees accessing the inter-american human rights system.
\end{abstract}

\section{Key Words}

Ancestral lands of indigenous land ownership, administrative responsibility, fundamental and collective rights of indigenous peoples and the Inter-American System 

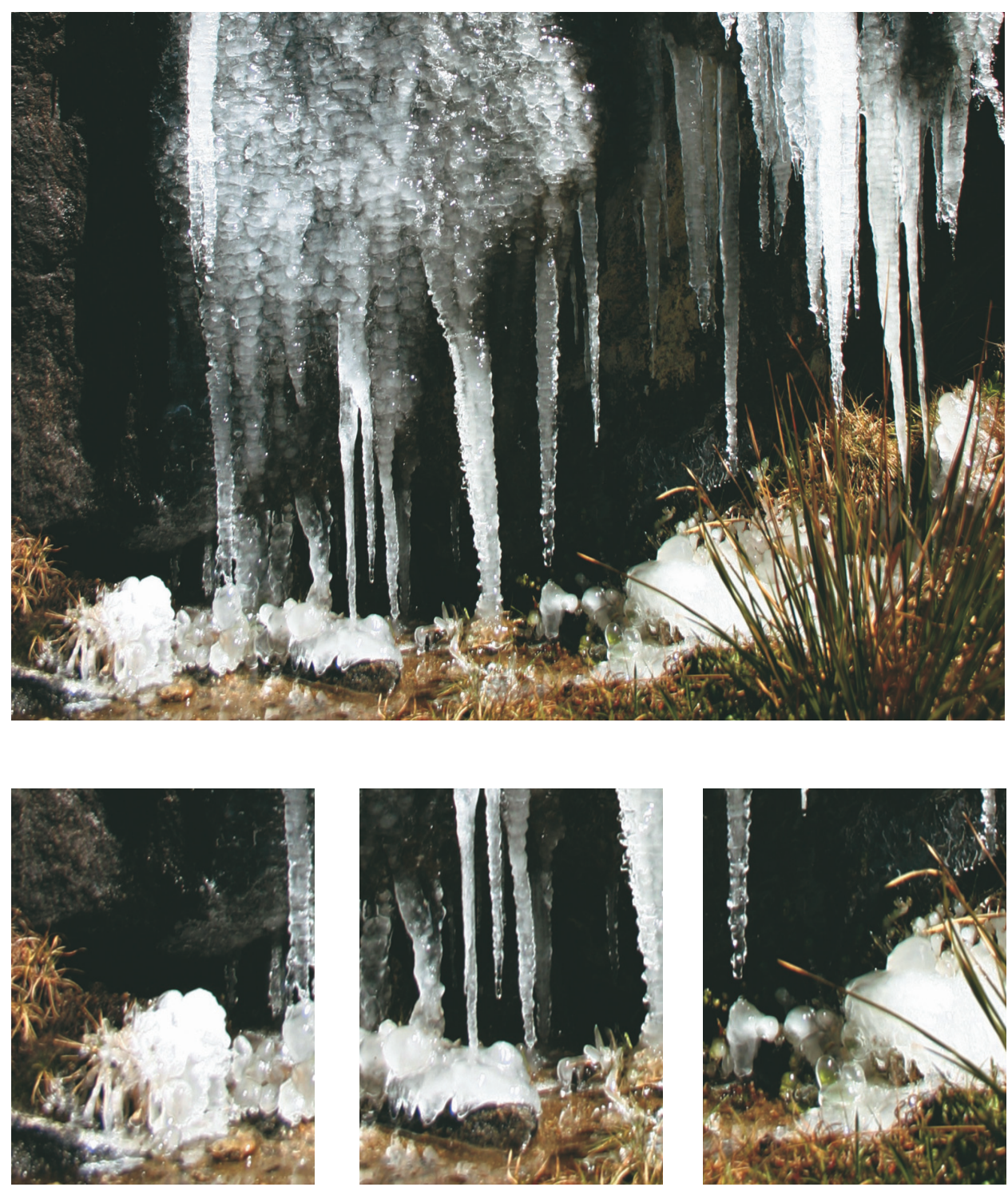

Cascada Congelada rumbo a "Morro Nevado" 


\section{RESPONSABILIDAD DEL ESTADO \\ COLOMBIANO EN EL MARCO DEL \\ DERECHO FUNDAMENTAL AL TERRITORIO \\ ANCESTRAL Y EL ACCESO A LA JUSTICIA \\ INTERAMERICANA*}

Fernando Aurelio Guerrero Cárdenas**

\section{Introducción}

Sin ser un fenómeno desconocido, la existencia de una situación fáctica en Colombia que ponga en riesgo el derecho fundamental de los pueblos indígenas de conservar su territorio ancestral, pone en entredicho el cumplimiento de la Constitución colombiana, sobre todo se relacionan posibles casos concretos, de los cuales se desprende claramente la posibilidad de configurarse una responsabilidad administrativa del Estado colombiano. Por otra parte, es sabido que dichas acciones u omisiones del Estado que prevean unos requisitos, pueden ser estudiadas por distintos mecanismos internacionales, entre otros, por la jurisdicción interamericana.

En este contexto, es preciso describir y analizar los elementos esenciales que puedan configurar una presunta responsabilidad por parte del Estado colombiano por omisiones concretas y delimitadas temáticamente que vulneran el derecho

\footnotetext{
* El presente artículo revisa acerca de la responsabilidad de Estado y el acceso a la justicia interamericana, se desarrolla en el marco del trabajo de la asignatura Metodología de la Investigación (Asesor Docente Janeth Milena Pacheco Baquero), presentado dentro de la Especialización en Derecho Administrativo de la Universidad Santo Tomás -Seccional Bucaramanga (Col).

** El equipo para el desarrollo del trabajo se conformo por: Fernando Aurelio Guerrero Cárdenas Oscar Javier Arias Ferreira, Darlin Milena Galván Lizarazo, July Natalia Gaona Prada, Edgar Fernando Pérez Rodríguez, Lisseth Mujica Rincón
} 
complejo colectivo fundamental de conservación y permanencia en el territorio ancestral a una comunidad indígena, sólo después de describir la problemática de los indígenas en todo aquello relacionado con su derecho al territorio ancestral, basados en los informes de los relatores de las Naciones Unidas (parte primera) y de aclarar los elementos jurídicos constitucionales colombianos dogmáticos y formales para establecer un concepto integral de territorio indígena (parte segunda), junto con las consecuencias normativas que pueden generarse de este concepto integral (parte tercera) $)^{1}$.

Sin embargo, más que un análisis que imputa responsabilidad, el presente escrito presenta un punto de partida para los que hacen escuela en el procedimiento jurídico para presentar acciones internacionales por responsabilidad internacional por omitir obligaciones aceptadas por convenios y tratados de proteger y garantizar los derechos colectivos de las comunidades dentro de sus territorios indígenas.

\section{Problemática de los derechos indígenas en relación a su territorio ancestral}

El reconocimiento y protección de los derechos territoriales de los pueblos indígenas es necesario para establecer condiciones sostenibles de paz y asegurar la supervivencia de los pueblos indígenas

Relator especial ONU

Actualmente las Comunidades Indígenas en Colombia según el Fondo de las Naciones Unidas para la Infancia (UNICEF, 2009), se encuentran distribuidos en 84 pueblos indígenas distribuidos en 32 departamentos del territorio nacional, los cuales tienen alrededor de 64 idiomas distintos, particular cosmovisión, historia y espiritualidad, cumpliendo así las características generales de una etnia ${ }^{2}$, donde se incluyen agricultores, recolectores y pescadores, así como comunidades campesinas indígenas y pequeños grupos nómadas, al igual que la creciente población indígena urbana.

En el SIDH se observan fallos de la Corte IDH como los Casos Awas Tingni contra Belice; Yakye Axa contra Paraguay; Los 12 Clanes Saramaka contra Suriname, llegando a la conclusión de incumplimiento para el efectivo reconocimiento y protección del derecho a la propiedad comunal de comunidades indígenas, y ordenando que se adopten las medidas necesarias para brindar protección judicial y dar efecto a los derechos colectivos e individuales de los pueblos indígenas en relación con los territorio ocupados y usados tradicionalmente. Esto da cuenta de la evolución que atravesara el SIDH en materia del reconocimiento de la dimensión del pueblo indígena como sujeto colectivo con determinados derechos colectivos que se garantizan con la protección de su territorio ancestral.

2 Una etnia según el Diccionario de la Real Academia, es una población en la cual los miembros se identifican entre ellos, normalmente con base en una real o presunta genealogía y ascendencia común, o en otros lazos históricos. Las etnias están también normalmente unidas por unas prácticas culturales, de comportamiento, lingüísticas, o religiosas comunes. Dichas comunidades comúnmente reclaman para sí una estructura social, política y un territorio. 
El Gobierno colombiano, conforme al último censo poblacional efectuado en el año 2005 por parte del Departamento Nacional de Estadística (DANE), señala que en el territorio residen 1.378 .884 indígenas que corresponden al 3,4\% de la población del país. Estos pueblos indígenas viven en resguardos, esto es, en territorios de propiedad colectiva ${ }^{3}$. En la actualidad, existen 710 resguardos titulados, ubicados en 27 departamentos y en 228 municipios del país, que ocupan una extensión de aproximadamente 34 millones de hectáreas, lo que equivale al 29.8\% del territorio nacional.

Con esto pareciese que la pluralidad y riqueza cultural de estos pueblos se perpetúa, ya que sus formas diversas de vida se encuentran ligadas de manera esencial a la tierra y al territorio, que les ha permitido mantener su identidad cultural; sin embargo, actualmente se puede deducir que existe un conflicto relacionado con el derecho a sus territorios, lo cual tiene una estrecha relación con el interés sobre los territorios étnicos, debido a diferentes hechos notorios (pobreza, marginación y exclusión), que apuntan a determinar como principal factor la ausencia de Estado. Con esto incluso se podría afirmar que el Estado de Colombia reconoce y protege la diversidad étnica y cultural de la nación.

De la misma manera el Estado colombiano puede demostrar que tiene un marco jurídico que ampara los derechos de los indígenas, entre otros a una educación bilingüe que afirme su identidad cultural, al carácter especial de sus tierras comunales y de resguardo y a sus patrimonios culturales, a la jurisdicción especial indígena y reconoce mecanismos especiales para el ejercicio de los derechos políticos de los pueblos indígenas, a dos cargos de senadores y hasta cinco cargos de Representantes a la Cámara, a ser sujetos de derechos fundamentales. Así mismo, el Estado colombiano ha ratificado el Convenio 169 de la Organización Internacional del Trabajo (OIT) donde acepta las obligaciones de consulta y participación de los pueblos indígenas en los asuntos que los afectan y una serie de normas que guardan relación con los derechos sobre sus tierras, la protección eficaz en materia de contratación y empleo, la seguridad social y los servicios de salud, la educación y los medios de educación.

Ante esta descripción jurídica ${ }^{4}$ que será tratada con mayor detenimiento más adelante, se puede inicialmente plantear que los miembros de dichas etnias cuentan con un amplio marco jurídico del Estado Colombiano y con todos los tratados de derechos humanos del sistema interamericano y la casi totalidad de los tratados de derechos humanos universales. Igualmente con una amplia y consolidada

3 Un resguardo según la Real Academia es una institución conformada por una parcialidad indígena que con un título de propiedad comunitaria posee su territorio y se rige para el manejo de este y de su vida interna por una organización ajustada al fuero indígena o a sus pautas y tradiciones culturales y cuyos objetivos, entre otros, apuntan hacia la protección del ambiente de un grupo étnico y cultural.

4 En una situación similar contemplada por la Corte Interamericana en el caso del pueblo negro de Saramaka contra Surinam. 
jurisprudencia de la Corte Constitucional que ha sido desarrollada con observancia de la Constitución Nacional de 1991.

A pesar de esto, la Comisión Interamericana de Derechos Humanos, en sus últimos informes no es muy benévola con el Estado en sus consideraciones. El tercer informe sobre la situación de los derechos humanos en Colombia del año 1999, señaló, en relación con el derecho al territorio que en sí garantiza un amplio catálogo de derechos antes mencionados, que a pesar de haber sido reconocidas alrededor de 30 millones de hectáreas de territorios indígenas,

"dichas reivindicaciones y aun la posesión de tierras ya reconocidas son obstaculizadas y opuestas en algunos casos por amenazas, hostigamientos $y$ atentados. Estos actos de violencia y amenazas provienen de diferentes sectores, pero frecuentemente de terratenientes grandes, colaborando con grupos paramilitares $y$, en muchos casos, con miembros o unidades de las fuerzas públicas de seguridad del Estado" (P.102, 1999).

Más recientemente, en su Informe sobre la situación de derechos humanos de los pueblos indígenas en el Estado de Colombia, el Relator de Naciones Unidas sobre Pueblos Indígenas, señaló en el año 2004, después de una visita al país, que

"en los últimos 15 años se registraron más de 2.660 casos de violaciones a los derechos humanos y al Derecho Internacional Humanitario contra pueblos indígenas".

Igualmente, el 9 de agosto de 2007, durante la celebración del día internacional de los pueblos indígenas, la Oficina del Alto Comisionado de la Organización de Naciones Unidas (ONU) para los Derechos Humanos indicó, en relación con el Estado de Colombia, que
"Las comunidades indigenas han afrontado y siguen afrontando una situación muy compleja, en la cual se combinan el desconocimiento reiterado de sus derechos económicos, sociales y culturales, y las múltiples y frecuentes agresiones a sus derechos civiles y politicos".

Esta situación de los derechos humanos de los pueblos y comunidades indígenas se contempla como crítica y preocupante también hoy en el año 2010, con base en el último informe del Relator Especial profesor Anaya, J. (2009) de la Organización de las Naciones Unidas sobre pueblos indígenas, al concluir su visita a Colombia en el año 20095. El Relator Especial observó que las sentencias de la Corte han favorecido a los pueblos indígenas, sin embargo, notó que persisten alegaciones de

5 "La situación de los derechos humanos de los indígenas de Colombia es grave, crítica y profundamente preocupante". Tal fue la conclusión en el año 2004 por el Relator Especial de las Naciones Unidas sobre la situación de los derechos humanos y las libertades fundamentales de los indígenas, Profesor Rodolfo Stavenhagen. En el año 2009 el actual Relator Especial, Profesor James Anaya, al concluir su visita al país, señaló respecto a esa evaluación del 2004. "Esa evaluación sigue siendo aplicable hoy, a pesar de algunas iniciativas importantes del Gobierno de Colombia durante los últimos años". 
violaciones de derechos humanos por miembros de la Fuerza Pública y que siguen sin ser resueltos varios casos con víctimas indígenas.

Hasta aquí se puede concretar, que existe una grave situación en Colombia respecto a las etnias indígenas y que hoy es una exigencia persistente de los pueblos indígenas en Colombia, relacionada con el derecho al territorio, para iniciar un fortalecimiento dirigido a satisfacer todas sus necesidades, que durante las últimas décadas, Colombia ha avanzado en el reconocimiento de los derechos territoriales de los pueblos indígenas en el país y que aún quedan muchos reclamos territoriales indígenas por resolver. Además, que la existencia de intereses comerciales extensivos en los recursos naturales ${ }^{6}$ de los territorios de los pueblos indígenas, amenazan en muchas ocasiones los derechos de los pueblos indígenas.

Es así, como la afectación de la tierra y el territorio ancestral se ha materializado, por lo cual es imperioso describir el marco jurídico formal y dogmático relacionado con la evidente afectación al derecho al territorio, los daños ocasionados a sus zonas ancestrales sagradas y espirituales y los daños ambientales que afectan sus recursos. Desde ese marco es preciso partir a un estudio jurídico que plantee los aspectos generales de una posible responsabilidad del Estado colombiano y si esta situación puede llegar a estadios judiciales internacionales.

\section{Hacia un concepto de territorio ancestral indígena como derecho}

Ante la problemática actual en la que se ve envuelta la optimización de los derechos indígenas en Colombia, el concepto de territorio ancestral indígena como derecho denota especial importancia, toda vez que de su descripción integral no excluyente de sus propiedades esenciales depende la realización de derechos fundamentales colectivos innominados, por lo cual dicho concepto debe incluir principalmente el derecho al reconocimiento de su posesión colectiva y a la garantía de perpetuidad de un conjunto de experiencias culturales, sociales y políticas que son inescindibles de los derechos territoriales.

Para Herreño, A. (2004), en la más reciente construcción del concepto de territorio ancestral han sido decisivos dos factores: a) la defensa comunitaria de estos derechos territoriales por parte de las organizaciones indígenas, que han presionado el desarrollo legislativo y las políticas de reconocimiento; b) la jurisprudencia desarrollada por la Corte Constitucional a través de una progresista hermenéutica ha

6 Esta situación se agrava por la realización de diferentes proyectos agrícolas, forestales, industriales, de grandes obras de infraestructura y de explotación de petróleo, que se desarrollan en sus territorios ancestrales. El desarrollo de este tipo de proyectos, unido al interés en la explotación de las riquezas naturales -de suelo y de subsuelo- que se encuentran en estos territorios - por tratarse de zonas de una alta biodiversidad, o poseedoras de riquezas minerales y de hidrocarburos que las convierten en especialmente estratégicas- ha generado un aumento de las violaciones a los derechos humanos, individuales y colectivos. 
ido clarificando el alcance y contenido de los derechos fundamentales colectivos de las comunidades indígenas.

Desde un punto de vista empírico para el desarrollo del objeto de este escrito, es conveniente adoptar una orientación de estudio jurídico en función de describir frente al derecho, el desarrollo que tiene dentro del ordenamiento jurídico y en la jurisprudencia, con el ánimo de que sean protegidos y garantizados todos los derechos que se derivan de esta propiedad colectiva. Sin embargo, el punto de partida de una conceptualización adecuada debe tener una clara descripción finalista de un territorio ancestral para las comunidades indígenas, para poder pasar ya a su desarrollo legal y finalizar con el tratamiento hermenéutico en la jurisprudencia.

Así las cosas, como primera medida, un territorio ancestral es aquel donde comunidades indígenas desarrollan y practican sus costumbres ancestrales, igualmente, donde practican sus propias formas de explotación de las tierras, ejercen la potestad colectiva sobre los recursos naturales que se encuentran en ellas, mantienen incólumes sus sitios sagrados, ejercen su milenaria forma de gobierno en muchos casos y su jurisdicción en forma autónoma, garantizan la permanencia como colectivo y mantienen la unidad con tranquilidad y seguridad al no mediar circunstancias de amenaza de expulsión, enajenación y alteración de sus propias concepciones de desarrollo y vida.

Desde este punto de partida el derecho al territorio ancestral denota especial importancia porque encuentra relación directa con el derecho colectivo a la subsistencia, ya que algunos grupos indígenas que conservan su lengua, tradiciones y creencias no conciben una existencia separada de su comunidad, luego jurídicamente requieren la garantía de derechos colectivos relacionados con el reconocimiento de derechos fundamentales al individuo; esto es difícil de interpretar para aquellos que conciben como base la prescindencia de concepciones diferentes como aquellas que no admiten sino una perspectiva individualista de la persona humana clásica basada en principios constitucionales fundamentales pero individuales y personales, y no en principios colectivos de democracia, pluralismo, respeto a la diversidad étnica y cultural y protección de la riqueza cultural.

Desde este punto de partida, lo que sigue es determinar un marco legal colombiano que garantice su realización. En esa línea la principal fuente jurídica que garantiza la existencia de los territorios indígenas y que cataloga expresamente los derechos fundamentales colectivos derivados de tal garantía es la Constitución Política (Muyuy, 1998; Fajardo, 1999) ${ }^{7}$, ya que incorporó dentro de su campo normativo el

7 Los autores señalan que la incursión de derechos catalogados expresamente como tales en la Constitución de 1991 referentes a las comunidades indígenas, es consecuencia de las luchas de los pueblos ancestrales en Colombia, debido a que las organizaciones indígenas lograron que sus reclamaciones a la propiedad colectiva de los territorios ancestrales se consagraran en la Constitución. Dichas luchas iniciaron por el liderazgo de Manuel Quintín Lame (El líder Quintín Lame fue privado de la libertad por el gobierno conservador en 1915) y José Gonzalo Sánchez. 
reconocimiento y defensa de las minorías étnicas, y de manera muy significativa, reservó en favor de las comunidades indígenas una serie de prerrogativas que garantizan la prevalencia de la integridad cultural, social y económica, su capacidad de autodeterminación administrativa y judicial, la consagración de sus resguardos como propiedad colectiva de carácter inalienable, y de los territorios indígenas como entidades territoriales al lado de los municipios, los distritos y los propios departamentos (C.P. art. 7, 1671?, 246, 286, 329, 330, entre otros) tal como lo manifestó la Honorable Corte Constitucional en la Sentencia T-007 de 1995.

Al abordar ahora el desarrollo jurisprudencial en vía de la materialización de las disposiciones colectivas constitucionales, las sentencias de la Corte Constitucional colombiana sobre derechos de los pueblos indígenas han jugado un importante papel en la construcción de la idea del territorio, al punto de tenerse hoy como referencia obligada pues consolidan en conjunto una nueva hermenéutica jurídica, coherente con los principios constitucionales de diversidad étnica y pluralismo jurídico (Sánchez, 2003).

Se encuentra un posible primer caso en la Honorable Corte Constitucional colombiana en la Sentencia T-443 de 1993, donde esboza tímidamente el derecho a la propiedad de una comunidad indígena. En 1995 la Corte relaciona el catálogo constitucional de derechos indígenas basado principalmente en el principio de protección de la diversidad étnica y cultural y de su reconocimiento, con el plano constitucional que protege la personería sustantiva a las diferentes comunidades indígenas, al explicar este último como un elemento instrumental que le confiere a una población indígena determinada, la practicidad de gozar de sus derechos fundamentales colectivos y exigir, por sí mismas, su protección cada vez que ellos les sean conculcados; lo que puede extraerse igualmente de los artículos 1, 7 y 14 de la Constitución Política de Colombia de 1991.

En 1996 la Corte Constitucional en la Sentencia T-672, empieza a interpretar al derecho de posesión como un derecho fundamental, lo cual sirvió de fundamento para que más adelante se entendiera éste como un derecho tutelable (de conformidad con las sentencias T-443 de 1993, T-672 de 1996 de la Corte Constitucional, entre otras), el cual para el caso de las posesiones indígenas fue objeto de desarrollo jurisprudencial (Corte Constitucional. Sentencia SU-039 de 1997) que desemboca en la garantía del derecho a la propiedad colectiva de las tierras ancestrales, ya que la Corte empieza a considerar que la comunidad indígena es sujeto de derechos fundamentales como colectivo, y que este es el presupuesto del reconocimiento expreso en la Constitución

Dentro de las nuevas organizaciones con carácter regional o gremial, se encuentran: Autoridades Indígenas de Colombia (AICO), la Organización de los Pueblos Indígenas de la Amazonía Colombiana (Opiac), la Organización Indígena de la Guajira (Yanama), la Organización Indígena Tayrona de la Sierra Nevada de Santa Marta (Gonawindua), entre otras; también se han conformado otras expresiones organizativas con fines electorales, como el Movimiento Indígena de Colombia, MIC y la Alianza Social Indígena (ASI). 
sobre la diversidad étnica y cultural de la nación colombiana.

En 1997, la Corte Constitucional en la Sentencia SU-039 de 1997, al analizar temas de explotación de recursos naturales en territorios ancestrales indígenas, toca el tema que nos ocupa en forma directa y enuncia con claridad los derechos fundamentales innominados a los cuales tienen derecho los pueblos indígenas y que tienen relación directa con sus territorios ancestrales, que determina que se deben tener estipulados como tales en el cuerpo de la Carta Fundamental, los cuales son expresados así: a) Derecho de participación de comunidad indígena; b) Derecho a la integridad de comunidad indígena; c) Derecho a la preservación de comunidad indígena

Sobre el derecho fundamental colectivo a la subsistencia, la Corte señaló en la Sentencia T-380 de 1993 que los derechos fundamentales de las comunidades indígenas no deben confundirse con los derechos colectivos de otros grupos humanos. La comunidad indígena es un sujeto colectivo y no una simple sumatoria de sujetos individuales que comparten los mismos derechos o intereses difusos o colectivos. En el primer evento es indiscutible la titularidad de los derechos fundamentales, mientras que en el segundo, los afectados pueden proceder a la defensa de sus derechos o intereses colectivos mediante el ejercicio de las acciones populares correspondientes. Entre otros derechos fundamentales, las comunidades indígenas son titulares del derecho fundamental a la subsistencia, el que se deduce directamente del derecho a la vida consagrado en el artículo 11 de la Constitución.

Aunque los derechos fundamentales colectivos innominados de los pueblos indígenas (sin ser un tema realmente interesante) no son el tema central de este escrito, si lo es el hecho de que fue el abordaje de estos temas en la Corte lo que generó que se construyera la base jurídica del concepto del territorio indígena como derecho ancestral, toda vez que la explotación de los recursos naturales en los territorios indígenas debe hacerse compatible con la protección que el Estado debe dispensar a la integridad social, cultural y económica de las comunidades indígenas, integridad que configura un derecho fundamental para la comunidad por estar ligada a su subsistencia como grupo humano y como cultura, lo cual encuentra sustento siempre y cuando se den garantías a la preservación del territorio ancestral, por tanto, este último adquiere así la connotación de derecho desde la interpretación dogmática de la Norma de normas.

Luego, la Sentencia SU-039 de 1997 de la Corte, es un antecedente jurisprudencial obligado para este tema, pues señala que los indígenas son sujetos de derechos fundamentales y que la Constitución reconoce que hay formas de vida social diferentes y debe otorgarse a estas comunidades personería sustantiva, pues eso es lo que confiere estatus para gozar de los derechos fundamentales y exigir protección. Igualmente señala en las Sentencias T-342 de 1994, T-188 de 1993, T-342/94 y T-652 de 1998, que la protección constitucional del principio de diversidad étnica y cultural 
implica un derecho a la formación de resguardos ${ }^{8}$ en cabeza de las comunidades indígenas no sólo porque son su fuente de subsistencia sino que constituyen elemento integral de su cultura y religiosidad. El derecho de propiedad colectiva ejercido sobre los territorios indígenas reviste una importancia esencial para las culturas y valores espirituales de los pueblos aborígenes.

Por otra parte dentro de la hermenéutica de la Corte, también se encuentra como primario el tema del derecho al ejercicio del gobierno y a la jurisdicción indígena, que también guarda relación directa con el derecho a su territorio ancestral. En las Sentencias T-254 de 1994 y C-139 de 1996, la Corte consideró que la jurisdicción indígena está integrada por cuatro elementos centrales, derivados del artículo 246 de la Constitución Política:

1. La posibilidad de tener sus propias autoridades judiciales.

2. La potestad que las autoridades judiciales tienen para establecer normas y procedimientos propios.

3. La sujeción de la jurisdicción y tales procedimientos a la Constitución y a la ley.

4. La competencia del legislador de buscar formas de coordinación entre la jurisdicción indígena y el sistema judicial.

Está jurisdicción indígena que da plena autonomía normativa y procedimental, tiene un carácter constitucional que le da el derecho a juzgar a sus propios naturales, el cual incluso tiene resorte internacional con la vinculación del Convenio 169 de la OIT (ratificado por la ley 21 de 1991. C.N. Art. 93. Sentencia T-634 de 1999). Sin embargo, este derecho junto a los anteriormente analizados, depende igual que los otros de la materialización del derecho al territorio ancestral.

Los anteriores elementos fácticos, jurídicos y de interpretación analizados en bloque, construyen un acercamiento a una acepción integral del concepto de territorio ancestral como derecho colectivo fundamental, que comprende dentro de su propiedades esenciales la acepción a derecho al reconocimiento de su posesión colectiva y a la garantía de perpetuidad de un conjunto de experiencias culturales, sociales y políticas que son inescindibles de los derechos territoriales, que entre otras cosas garantizan la realización de derechos fundamentales colectivos innominados, a participar en aspectos que tienen que ver con su población y su territorio ligados al

8 La Corte Constitucional en Sentencia T-634 de 1999 señaló en relación con el concepto de territorio ancestral y el resguardo que: "Como dentro de la juridicidad occidental es un contrasentido que la tierra sea sujeto del derecho, entonces, hay que inferir que la Constitución le otorga "derechos" es al territorio del resguardo como una entidad que en su identidad no solo expresa parte de nuestra nacionalidad colombiana, sino que es un concepto que también se ubica en el terreno de la cultura. En consecuencia, los resguardos son algo más que simple "tierra" y algo menos que "territorio indígena"; es decir, que no son términos iguales en la conceptualización constitucional, aunque, en una ley de ordenamiento territorial, geográficamente podrían coincidir. Pero, actualmente, todavía no se puede decir que un resguardo es una Entidad Territorial". 
derecho a la identidad como etnia porque tiene relación con la supervivencia cultural y encuentra su fundamento en las normas de la Constitución antes citadas y en el derecho a la libre autodeterminación de los pueblos, reconocido en el artículo $9^{\circ}$ de la Carta Política y en el artículo $1^{\circ}$ del Pacto de derechos civiles y políticos de 1966, con mecanismos que garantizan su protección, como son la participación de la comunidad en las decisiones que se adopten para autorizar dicha explotación, que jurídicamente se concibe como la Consulta Previa.

En la actualidad la idea del territorio se concreta en el interés de la adjudicación y titulación colectiva de las tierras ancestrales de las comunidades indígenas, con el fin no sólo de preservar la identidad étnica sino también de acceder a las garantías legales derivadas de la organización territorial del Estado (competencias políticoadministrativas y presupuestales según el tenor del artículo 287 de la Constitución Política).

En la definición actual de los territorios étnicos no sólo se juega el problema de la subsistencia económica de estos grupos: ellos han hecho y harán ejercicios de poder y resistencia de cara a poderosos intereses del capital nacional y transnacional que desean apropiarse de importantes porciones de la selva húmeda tropical colombiana con sus innumerables riquezas hídricas, minerales y biológicas. Titular territorios colectivos hoy es una manera de crear inmunidades frente al modelo capitalista de desarrollo y de esta situación son plenamente conscientes los pueblos originarios.

De la Carta se infiere, entonces, que la propiedad colectiva de los resguardos obedece a que en la concepción indígena existe una unidad inescindible entre pueblo y territorio comunal. Por eso se convino en su carácter de tierras inalienables que no son objeto de venta o transacción.

El derecho de propiedad colectiva ejercido sobre los territorios indígenas reviste una importancia esencial para las culturas y valores espirituales de los pueblos aborígenes. Esta circunstancia es reconocida en convenios internacionales aprobados por el Congreso, donde se resalta la especial relación de las comunidades indígenas con los territorios que ocupan, no sólo por ser éstos su principal medio de subsistencia sino, además porque, constituyen un elemento integrante de la cosmovisión y la religiosidad de los pueblos aborígenes. Adicionalmente, el Constituyente resaltó la importancia fundamental del derecho al territorio de las comunidades indígenas.

Sin este derecho, los anteriores (derechos a la identidad cultural y a la autonomía) son sólo reconocimientos formales. El grupo étnico requiere para sobrevivir del territorio en el cual está asentado, para desarrollar su cultura. Presupone el reconocimiento al derecho de propiedad sobre los territorios tradicionales ocupados y los que configuran su hábitat.

Así las cosas, lo principal en el resguardo es la forma de propiedad colectiva reconocida en la constitución e interpretada por la Corte Constitucional a través de subreglas como la de ámbito territorial, gracias a las cuales se ha podido amparar en muchas circunstancias los derechos colectivos de las comunidades. Este retorno a la propiedad colectiva como evolución del constitucionalismo de 1991 ha sido tan 
decisivo para afirmar la noción del territorio ancestral, que es difícil argumentar que se trata sólo de una conquista alcanzada en las luchas sociales por la tierra. Debe reconocerse que en la construcción reciente de la idea del territorio indígena ha jugado un importante papel la hermenéutica constitucional desarrollada por la Corte.

Al lado de la jurisprudencia garantista, el concepto de territorialidad ancestral ha encontrado consenso porque persiste el interés de los pueblos indígenas de ganar autonomía (en ejercicio del principio de respeto a la diversidad étnica y cultural) para administrar política, jurídica y financieramente los territorios colectivos en oposición al modelo centralista del Estado. También es claro que dicho concepto se ha convertido en una herramienta política que expresa la resistencia social respecto de los factores que han y están amenazando expulsar a las comunidades de las tierras que históricamente les han pertenecido.

El derecho de participación de la comunidad indígena como derecho fundamental (Art. 40-2 C.P.), tiene un reforzamiento en el Convenio número 169 de la OIT, aprobado por la ley 21 de 1991, el cual está destinado a asegurar los derechos de los pueblos indígenas a su territorio y a la protección de sus valores culturales, sociales y económicos, como medio para asegurar su subsistencia como grupos humanos. De este modo, el citado Convenio, que hace parte del ordenamiento jurídico en virtud de los Art. 93 y 94 de la Constitución, integra junto con la aludida norma un bloque de constitucionalidad que tiende a asegurar y hacer efectiva dicha participación.

\section{Consecuencias jurídicas del territorio ancestral como derecho (marco jurídico)}

\section{"Todos los pueblos tienen el derecho de libre determinación.En virtud de este derecho establecen libremente su condición política y proveen así mismo a su desarrollo económico, social, y cultural”. ONU-1968}

Por ser el Estado colombiano un Estado Social y Democrático de Derecho, de la Constitución Política podemos abstraer una protección especial a las poblaciones indígenas más allá del reconocimiento como entidad territorial. En consecuencia, se otorga rango constitucional a los derechos y garantías consagradas en la legislación interna respecto de las poblaciones indígenas, se respeta su diversidad étnica y cultural a través de la promoción, el fortalecimiento y el cuidado su autonomía sociopolítica, económica, cultural y jurisdiccional.

Con base a lo descrito por el indígena Muyuy, G (1998), se pueden resumir los derechos reconocidos a los pueblos indígenas en la Constitución, agrupándolos de la siguiente manera:

1. Derecho de participación en las decisiones culturales de la Nación (artículo 2); Derecho de asociación (artículo 38).

2. Derecho a la igualdad de los indígenas como personas y de las poblaciones indígenas (artículo 13); Derecho a la vida de los indígenas y a la existencia de las comunidades indígenas (artículo 11). 
3. Derechos de identidad cultural: el Estado reconoce la diversidad étnica y cultural de la nación colombiana (artículo 7), la identidad cultural de las comunidades nativas (artículo 310); la oficialidad de las lenguas indígenas en sus territorios, la etno-educación y la enseñanza bilingüe (artículo 10, literal e; artículo 68, numeral 5); la libertad de conciencia y de cultos (artículos 18 y 19), la defensa del patrimonio cultural (artículo 72), la igualdad y dignidad de todas las culturas como fundamento de la nacionalidad (artículo 70). Además, la facultad de ejercer su propia justicia (artículo 246).

4. Derechos de autonomía territorial: la conformación de las entidades territoriales indígenas autónomas de conformidad con la ley orgánica de ordenamiento territorial (artículos 1, 287 y 329) reconocen a las tierras ancestrales como algo más que simples bienes raíces y las ligó a la existencia étnica y cultural de las comunidades; El derecho de propiedad colectiva de los resguardos y se consideran estas tierras como inalienables, imprescriptibles e inembargables (artículo 63); Igualmente, se establece que los territorios indígenas son entidades territoriales con autonomía para gobernarse y gestionar su desarrollo (artículo 286). Propiedad Privada y propiedad de las poblaciones indígenas sobre sus territorios (artículo 58).

5. Derechos de autonomía política y social: el derecho a elegir dos representantes indígenas para el Senado de la República (artículo 171); la posibilidad de elegir un representante más en la Cámara (está aún sin reglamentar (artículo 176), el reconocimiento de la doble nacionalidad de los indígenas de territorios fronterizos (artículo 96, literal c), la participación y gobernación de las comunidades indígenas, estableciendo las funciones de sus representantes y reglamentando todo lo relacionado con la explotación de los recursos naturales de los territorios (artículo 330).

6. Derecho de ejercicio autónomo de una jurisdicción especial indígena: El Constituyente otorgó a los resguardos “ámbito territorial”, lo que implica un efecto legal inmediato, limita algunas competencias propias del Estado dentro de este territorio, para que se rija autónomamente por sus propias normas, usos y costumbres, las autoridades de los pueblos indígenas podrán ejercer funciones jurisdiccionales dentro de su ámbito territorial, de conformidad con sus propias normas y procedimientos, siempre que no sean contrarios a la Constitución y leyes de la República (artículo 246).

7. Derechos ambientales y de control sobre la explotación de recursos naturales en sus territorios: derecho al goce de un ambiente sano (artículo 79), a conservar los recursos naturales a partir de una concepción de desarrollo sostenible y el derecho a consulta previa para la exploración y explotación de recursos naturales en territorios indígenas (artículo 80), entre otros.

8. Derechos económicos: los resguardos se asimilan a los municipios, con el propósito de que participen en los ingresos corrientes de la Nación y así proyecten de manera autónoma su desarrollo (artículo 357). 
Como podemos observar, la Constitución Política de Colombia ha reconocido a las Comunidades Indígenas su autonomía política, económica y cultural, así mismo les ha otorgado los mismos derechos que tienen todos los miembros del Estado colombiano y, adicional a ello, protege de manera especial el territorio en el que tienen asiento como propiedad colectiva con la finalidad de proteger sus derechos fundamentales y su diversidad cultural, pues como se ha analizado hasta aquí, la existencia de las comunidades y la perpetuidad del legado de sus ancestros, se encuentran ligados al territorio ancestral indígena por connotaciones culturales y religiosas. Como consecuencia de lo anterior, los miembros de las comunidades indígenas gozan de un fuero especial, el cual les permite ser juzgados conforme a sus propias normas, procedimientos y autoridades.

Dentro de este marco jurídico general sobresale la Ley 21 de 1991 mediante la cual el Estado Colombiano ratificó el Convenio 169 de la OIT, el cual constituye pilar fundamental de los derechos ${ }^{9}$ que respecto de sus territorios tienen las poblaciones indígenas y los debere ${ }^{10}$ que frente a los mismos tiene el Estado. En esta ley encontramos disposiciones que protegen a las poblaciones indígenas que han sido desplazadas de sus tierras, permitiéndoles el regreso a ellas una vez cesadas las causas que los obligaron a abandonarlas, y en caso que no sea posible su retorno obliga al Estado Colombiano a entregar tierras a estas comunidades para garantizar su subsistencia y desarrollo futuro; igualmente protege los territorios indígenas de terceras personas que pretendan apropiarse de ellos.

En este orden de ideas en nuestro Estado Social de Derecho, existe un marco jurídico general que se resume así: la legislación general de la República que se refiere a todo el compendio de leyes y normas aplicables a todas las personas que integran el territorio nacional; la Legislación Especial Indígena conformada por Convenios y Tratados Internacionales ratificados por Colombia y por las normas constitucionales, nacionales, departamentales y municipales; los Sistemas Normativos Propios conformados por las instituciones, normas, costumbres usos, procedimientos, métodos de control social de la tradición cultural de cada pueblo.

9 Articulo 13 "Al aplicar las disposiciones de esta parte del Convenio, los gobiernos deberán respetar la importancia especial que para las culturas y valores espirituales de los pueblos interesados reviste su relación con las tierras o territorios, o con ambos, según los casos, que ocupan o utilizan de alguna otra manera, y en particular los aspectos colectivos de esa relación (....)".

10 Articulo 14 "Deberá reconocerse a los pueblos interesados el derecho de propiedad y de posesión sobre las tierras que tradicionalmente ocupan. Además en los casos apropiados, deberán tomarse medidas para salvaguardar el derecho de los pueblos interesados a utilizar tierras que no estén exclusivamente ocupadas por ellos pero a las que hayan tenido tradicionalmente acceso para sus actividades tradicionales y de subsistencia (...) Los gobiernos deberán tomar medidas que sean necesarias para determinar las tierras que los pueblos interesados ocupan tradicionalmente y garantizar la protección efectiva de sus derechos de propiedad y posesión. Deberán instituirse procedimientos adecuados en el marco del sistema jurídico nacional para solucionar las reivindicaciones de tierras formuladas por los pueblos interesados". 
En tercer lugar, dentro del marco legal relacionado con los territorios ancestrales indígenas, es importante seguir con el fenómeno jurídico de la Consulta Previa, entendido de acuerdo a la Ley 99 de 1993 (artículo 76), como un proceso de consulta a representantes de pueblos indígenas en ejercicio del mecanismo de participación con el fin de ser un instrumento para preservar ante cualquier actividad relacionada con su territorio, la integridad étnica, social, económica y cultural de las comunidades de indígenas y para asegurar, por ende, su subsistencia como grupo social. De este modo dice la Corte $^{11}$ :

(...) la participación no se reduce meramente a una intervención en la actuación administrativa dirigida a asegurar el derecho de defensa de quienes van a resultar afectados con la autorización de la licencia ambiental, sino que tiene una significación mayor por los altos intereses que ella busca tutelar, como son los atinentes a la definición del destino y la seguridad de la subsistencia de las referidas comunidades.

Este fenómeno encuentra desarrollo jurisprudencial especialmente bajo la problemática de empresas nacionales y extranjeras que buscan lograr la explotación de los recursos naturales que se encuentran en dichos territorios indígenas sobre lo cual la Corte argumentó:
(...) precisamente, para asegurar la subsistencia del grupo se ha previsto, cuando se trate de realizar la explotación de recursos naturales en territorios indigenas, la necesidad de la participación de la comunidad en las decisiones que se adopten para autorizar dicha explotación. De este modo, el derecho fundamental de la comunidad a preservar la referida integridad étnica y cultural se garantiza y efectiviza a través del ejercicio de otro derecho que también tiene el carácter de fundamental, en los términos del Art. 40, numeral 2 de la Constitución, como es el derecho de participación de la comunidad en la adopción de las referidas decisiones, a través del mecanismo de la consulta, que adquiere la connotación de derecho fundamental, pues se erige en un instrumento que es básico para preservar la integridad étnica, social, económica y cultural de las comunidades de indígenas y para asegurar, por ende, su subsistencia como grupo social(Corte Constitucional Sentencia SU- 039 de 1997).

Es muy importante tener presente lo dispuesto en la Constitución Política de 1991 que en su artículo 288 prescribe que un territorio ancestral debe ser considerado jurídicamente como entidad territorial, sin embargo estipula que para que sean reconocidas como tales, es necesaria la expedición de una Ley Orgánica de Ordenamiento Territorial (LOOT) que establezca la distribución de competencias entre la Nación y las respectivas entidades territoriales.

Ahora bien, este mandato constitucional encuentra respuesta en ocho proyectos

11 Sentencia Corte Constitucional Referencia: Expediente T-84771, Peticionario: Jaime Córdoba Triviño, Defensor del Pueblo, en representación de varias personas integrantes del Grupo Étnico Indígena U'WA. 
de ley de ordenamiento territorial que han cursado en la Rama Legislativa, en lo que corrido de casi veinte (20) años de vigencia de la Carta constitucional colombiana. De dichos intentos ninguno ha prosperado debido a las grandes tensiones en el parlamento que encierran diversas discusiones políticas ${ }^{12}$.

Al respecto se puede decir que la Ley Orgánica de Ordenamiento Territorial (LOOT) se debate respecto a los intereses de los pueblos indígenas bajo estos criterios:

1. En la LOOT se debe disponer la creación de las Entidades Territoriales Indígenas (ETI).

2. En la LOOT debe prevalecer un criterio de contigüidad.

3. En la LOOT debe regular el derecho de consulta previa.

4. La LOOT debe establecerse en el marco de una democracia que protege la diversidad y la interculturalidad etno-pluralista.

5. La LOOT debe garantizar el respeto de la autonomía en el gobierno, en el ejercicio de las decisiones presupuestales y en el manejo ambiental de los territorios.

Hasta aquí se puede afirmar que en Colombia no se han desarrollado los territorios ancestrales indígenas como entes territoriales por omisión legislativa de casi veinte años, a pesar de que Colombia es un Estado Social de Derecho organizado en forma de República Unitaria y con autonomía de sus entidades territoriales ${ }^{13}$.

\section{Posible responsabilidad administrativa del estado colombiano en relación con el estado de cosas de los territorios ancestrales}

Para umplir con el propósito modesto de describir presuntas responsabilidades administrativas derivadas de las situaciones fácticas anteriormente señaladas, es oportuno y pertinente delimitar la sospecha en dos figuras jurídicas de gran importancia que revisten jerarquía frente a los derechos vinculados al territorio ancestral de las comunidades indígenas y frente al deber de garantía del Estado.

12 En la Sentencia T-634 de 1999, la Corte Constitucional expresó que el hecho de no haberse expedido la ley de ordenamiento territorial no es un obstáculo para la aceptación y desarrollo de la identidad y autonomía indígena en los resguardos a los que la misma Constitución les reconoce derechos.

13 Dentro del marco jurídico se pueden consultar adicionalmente: El decreto 2164 de 1995 que define los territorios indígenas, las comunidades o parcialidad indígena, reservas indígenas, autoridad tradicional, cabildo indígena y establece el procedimiento a seguir para constituir, reestructurar, sanear y ampliar los Resguardos Indígenas; La Ley 387 de 1997 donde se adoptan medidas para la prevención y atención del desplazamiento forzado; El decreto 250 de 2005, por el cual se establece la protección de los derechos de propiedad y posesión sobre los territorios de los pueblos indígenas afectados por el desplazamiento; La Ley 1152 de 2007 (Estatuto de Desarrollo Rural) en el capítulo I del título VI sobre Resguardos Indígenas y Minorías Étnicas que asigna competencia al Ministerio de Interior y Justicia para el estudio de las solicitudes de tierras de estas comunidades y señala que el Ministerio Público se encargará de hacer el seguimiento y control de los respectivos procesos de ampliación, saneamiento, constitución de territorios indígenas. 
Como consecuencia se examinan dos fenómenos jurídicos sin pretender que sean los únicos.

Como primer elemento hemos de analizar la omisión legislativa que atañe a la expedición de la Ley de Ordenamiento Territorial, teniendo como tales:

1. La no expedición del precepto dirigido a ejecutar el deber concreto que le ha impuesto la Constitución al legislador.

2. El cumplimiento del deber impuesto por la Constitución, pero con favorecimiento a ciertos grupos en perjuicio de otros.

3. Cuando en desarrollo de ese mismo deber, el legislador en forma expresa o tácita, excluye a un grupo de ciudadanos de los beneficios que otorga al resto.

4. Cuando el legislador, al regular o construir una institución, omite una condición o un ingrediente que de acuerdo con la Carta, sería una exigencia esencial para armonizar la norma con ella.

Estas omisiones, han sido catalogadas por la doctrina como la falta total de regulación normativa, frente a cualquier aspecto de la realidad regulable. Como por sustracción de materia, la ausencia íntegra de normatividad no puede ser cotejada con ningún texto, lo cual incluye por supuesto el de la Constitución, la jurisprudencia admite que frente a este tipo de omisiones el Juez constitucional se encuentra impedido para ejercer el juicio correspondiente.

De esta manera lo manifestó la Corte Constitucional, en la sentencia C-1083 del 5 de Noviembre de 2008, Magistrado Ponente: Dr. Mauricio González Cuervo:
...La acción pública de inconstitucionalidad si bien permite realizar un control más o menos extenso de la labor legislativa, no autoriza la fiscalización de lo que el legislador genéricamente ha omitido, conforme a las directrices constitucionales (...). Por esta razón, hay que excluir de esta forma de control el que se dirige a evaluar las omisiones legislativas absolutas: si no hay actuación, no hay acto qué comparar con las normas superiores; si no hay actuación, no hay acto que pueda ser sujeto de control. La Corte carece de competencia para conocer de demandas de inconstitucionalidad por omisión legislativa absoluta.

Lo dicho pone de presente la dificultad de acceder a la rama jurisdiccional para buscar resguardo normativo y amparo en procura de obtener una consecuencia legal frente a la LOOT. Así las cosas, existe ausencia de acción alguna que permita exigir al Estado el cumplimiento de los fines propuestos en la Constitución Política de Colombia, configurándose de esta manera la omisión legislativa.

Como segundo tema relevante, encontramos la responsabilidad de la Nación dentro del marco de la Consulta Previa, necesaria dentro de las actividades en las que el Estado regula los diferentes aspectos de la vida de los territorios indígenas. En este sentido la Universidad del Rosario, sintetiza en la voz de la Doctora Rodríguez, G. (2005) que la Constitución de 1991 al imponer el deber de proteger la diversidad cultural tanto a los particulares como al Estado, hace del mecanismo de la Consulta 
Previa a las Comunidades indígenas una figura fundamental para el cumplimiento de este deber y lo constituye en un asunto prioritario para el Estado cuando sus actuaciones estén relacionadas con los territorios indígenas ${ }^{14}$.

Dentro de los diversos conflictos suscitados en el Estado Colombiano relacionados con el tema en cuestión, sobresalen los casos con el territorio ancestral de los indígenas U’wa en relación con la intención de explotar su territorio atávico para la obtención de hidrocarburos y el caso con el pueblo Embera Katío por la generación de energía en la represa de Urrá en el Alto Sinú, entre otros.

Es importante recordar que la Consulta Previa, se cataloga como uno de los derechos que adquiere el rango de fundamental en los pueblos indígenas, ya que con dicha herramienta podrán resolver sobre medidas (legales o administrativas) o cuando se establezca que en dichos territorios se pretendan realizar propósitos, obras o actividades dentro de sus espacios ancestrales, se pretende de esta manera resguardar su integridad cultural, social, económica y garantizar el derecho fundamental a la participación, como eje fundamental de una sociedad pluralista.

Ahora ante una situación fáctica en la que se presente en acatamiento o indebida ejecución de una consulta previa por parte del Estado colombiano a un pueblo indígena respecto a su territorio ancestral, se puede considerar afirmar que la polémica vulnera las premisas constitucionales de las poblaciones indígenas, lo cual podría constituir un marco situacional que si llegase a tener un nexo causal con daños antijurídicos a su comunidad que produciría necesariamente una responsabilidad del Estado al haber afectado los territorios ancestrales en actividades que irrumpen con la intimidad de los pueblos y territorios indígenas.

Lo anterior implica que exista responsabilidad del Estado y por ello se persiga su carga a favor los sujetos pasivos de su acción, se buscan los mecanismos que encuentren resarcir los daños ocasionados con sus actuaciones.

En esa línea, una comunidad indígena encontrará dentro de la codificación jurídica colombiana dispositivos especialmente en las disposiciones normativas constitucionales y administrativas derechos aplicables en los tribunales nacionales.

Es pertinente complementar lo anterior con la estipulación y regulación del derecho a la consulta previa en normas internacionales, como el convenio 169 de la Organización Internacional del Trabajo (OIT) que entre otras cosas estipula deberes y compromisos para el Estado como la implementación de una política pública que garantice y dé amparo a los derechos de los pueblos indígenas. Sin embargo, debemos advertir que el Estado Colombiano se ha negado a ratificar la declaración Universal de los Derechos de los Pueblos Indígenas adoptada por la Organización de Naciones

14 La Corte Constitucional ha identificado como un problema persistente, la falta de consulta previa en decisiones que afectan a los territorios indígenas. En este sentido, recuerda la Corte que se han declarado inconstitucionales decisiones administrativas y leyes, más recientemente la Ley General Forestal y el Estatuto de Desarrollo Rural, por no haber sido consultadas adecuadamente con los pueblos indígenas. 
Unidas (ONU) el 13 de Septiembre de 2007, que dilucida la intención política de turno que se centra en la seguridad democrática como lo afirman los centros de noticias ${ }^{15}$.

Así las cosas, se considera que los hechos pueden tomar una dirección ajustada hacia una presunta responsabilidad administrativa del Estado Colombiano ante la omisión del mandato constitucional de expedir y sancionar una ley orgánica de ordenamiento territorial; en segundo lugar que el Gobierno en su actuar debe tener de presente como parte de una adecuada función pública y administrativa, la realización de la Consulta Previa a las Comunidades Indígenas para no incurrir en omisiones que lleven a generar su responsabilidad administrativa.

\section{Posibilidad de acceder ante el sistema interamericano casos relacionados con los territorios ancestrales}

Vemos que el derecho internacional en su amplia universalidad jurídica no es sólo de concatenación entre Estados, sino que los sujetos como personas naturales en virtud de los acuerdos y tratados se hacen acreedores a las prerrogativas de las normas del derecho internacional; durante mucho tiempo los indígenas fueron sometidos a una desprotección jurídica total, hasta que en 1982 la Naciones Unidas crearon una comisión en miras de prevenir la discriminación y generar una protección a todas las minorías en la órbita internacional; es así como en estudio de las normas consagradas en mecanismo o herramientas internacionales encontramos la protección de los derechos humanos en relación a los pueblos indígenas a través de un procedimiento ante la comisión interamericana y la corte interamericana claro y expreso.

Actualmente, aunque no existe un procedimiento especial para las poblaciones indígenas, si hay un procedimiento internacional general para solicitar el reconocimiento de derechos humanos que estén siendo violados por los Estados miembros de la Organización de Naciones Unidas. Las poblaciones indígenas al recibir el mismo trato ante la ley que los demás miembros del Estado, pueden acudir a esta jurisdicción internacional, apelar al principio de igualdad consagrado no sólo en la Carta Política sino, además, en el Pacto Internacional de Derechos Civiles y Políticos en sus artículos 21 y 26, la Declaración Americana de los Derechos y Deberes del Hombre en su artículo 2 y la Declaración Universal de Derechos Humanos en su Artículo 7.

15 Centro Independiente de Noticias (2008). Recuperado el día 11 de noviembre de 2009 del sitio Web http://cinoticias.com/tag/etnocidio/ “(...) lo que pone de presente las intenciones de este gobierno respecto de los grupos indígenas del País y se constituye en la más clara muestra de su política anti indigenista. De esta manera afecta gravemente nuestros derechos ancestrales, a la Autodeterminación, a la autonomía y a la propiedad del territorio y los recursos naturales". Centro Independiente de Noticias (2008). Recuperado el día 11 de noviembre de 2009 del sitio Web http:// cinoticias.com/tag/etnocidio/ 
En primer lugar, antes de acudir a la Corte Interamericana es necesario acudir a la vía administrativa ante la Comisión Interamericana de Derechos Humanos, que recibe peticiones respecto de la presunta violación de los derechos reconocidos (derecho al territorio ancestral indígena), como se puede extraer del artículo 23 del reglamento de la Comisión Interamericana de Derechos Humanos y del Artículo 44 de la Convención Americana Sobre Derechos Humanos.

Para que estas peticiones sean admitidas por la Comisión, deben cumplir el lleno de los requisitos consagrados en el artículo 46 de la convención americana, entre los cuales tenemos:

1. Agotar la vía de la jurisdicción interna del Estado donde se generó el conflicto. Si la legislación interna no protege tales derechos, no se requiere agotar este requisito.

2. Presentar la petición dentro de seis (6) meses a partir de la fecha en que el presunto lesionado en sus derechos haya sido notificado de la decisión definitiva

3. La petición debe estar fuera del conocimiento de otra instancia internacional

4. Contener el nombre, la nacionalidad, la profesión, el domicilio y la firma de quien presenta la petición.

5. Falta de relación o nexo entre los hechos y la violación.

Una vez admitida la solicitud, la Comisión solicitará al Gobierno del Estado implicado que dentro del término señalado envíe la información que tenga a su alcance respecto de los hechos; una vez recibida tal información o transcurrido el término sin que se aporte, se verificará la subsistencia de los motivos de la petición y según el caso se archiva, se inadmite, se declara la improcedencia de la petición o se realiza una investigación; en caso se iniciar investigación podrá la Comisión solicitar información pertinente al Estado implicado y recibirá las exposiciones verbales o escritas que presenten los interesados, las cuales se pondrán a disposición de las partes interesadas, a fin de llegar a una solución amistosa. Cuando se trata de situaciones graves con la simple presentación que cumpla el lleno de los requisitos, la Comisión puede ordenar la realización de la investigación previa.

Una vez agotado el procedimiento ante la Comisión (que constituye un filtro para acceder a la Corte) será competente para conocer del asunto la Corte Interamericana de Derechos Humanos quien deberá culminar el proceso con un fallo actuando como Juez máximo, con la finalidad de garantizar el goce los derechos conculcados. El procedimiento a seguir se encuentra claramente regulado en la Convención Americana.

El fallo de la Corte debe ser motivado y resolver de fondo la situación; éste no admite apelación. Dentro de los noventa (90) días siguientes a la notificación del fallo, las partes podrán presentar peticiones respecto del alcance del mismo, las cuales serán resueltas por la Corte. Una vez en firme la sentencia, los estados miembros deberán acatar las órdenes de la corte. Si el fallo dispone indemnización compensatoria, el mismo podrá ser ejecutado en el estado vinculado por el procedimiento interno 
vigente para la ejecución de sentencias contra el Estado.

El artículo 45 del reglamento de la comisión interamericana de derechos humanos, regula los elementos a tener en cuenta para que el proceso sea sometido al conocimiento de la Corte Interamericana, así:

“a) La posición del peticionario; b) la naturaleza y gravedad de la violación; c) La necesidad de desarrollar o aclarar la jurisprudencia del sistema; y d) el eventual efecto de la decisión en los ordenamientos jurídicos de los Estados miembros"

Es un poco inusual que cualquier ciudadano acuda a la comunidad internacional a elevar protección de derechos humanos que le sean vulnerados, sin embargo existen diversos casos de importancia internacional, en los que el Estado colombiano ha sido declarado responsable administrativamente por las actuaciones de sus agentes generadoras de violaciones a derechos humanos de personas.

Dentro de los casos a analizar encontramos tres importantes que han sido estudiados por la Corte Interamericana de Derechos Humanos en donde se menciona o se relaciona la responsabilidad del Estado colombiano.

Así pues tenemos, el caso de la Masacre de Mapiripan ${ }^{16}$ vs. Colombia (2005), La Masacre de la Rochela vs. Colombia (2007) y Escué Zapata vs. Colombia (2007) - este caso en especial se encuentra ligado con un miembro de una comunidad indígena -, en los que el Estado colombiano ha sido declarado responsable y condenado a reparar los perjuicios causados a las víctimas, de manera material a través de las figuras de verdad, justicia y reparación.

\section{(...) Colombia es un Estado que se encuentra obligado internacionalmente debido a la suscripción de varios convenios y tratados relativos al respeto $y$ preservación de las normas pertenecientes al denominado Derecho Internacional Humanitario. Asi mismo, internamente cuenta con una serie de normas que se dirigen a la preservación del mismo cuerpo normativo mencionado. La pregunta a resolver radica en procurar establecer qué puede ocurrir en materia de responsabilidad internacional si el Estado colombiano vulnera normas pertenecientes al Derecho Internacional Humanitario o, si teniendo a su disposición en el ordenamiento interno normas para preservarlo, no les da la aplicación debida y oportuna." (Cruz, J.; Rodríguez, A. (1999))}

Como una manera de ejemplificar un poco más la responsabilidad del estado en la vulneración de derechos humanos, tenemos el caso de la Masacre de Ituango vs. Colombia (2006), desatado debido al asesinato cometido por los paramilitares de un grupo de personas que se encontraban en las veredas el Aro y la Granja. En este caso, como en otras ocasiones, el Estado Colombiano fue declarado responsable por

16 En el caso de la Masacre de Mapiripan vs. Colombia, el Estado Colombiano fue condenado responsable, por no haber ejercido en forma oportuna mecanismos para evitar la creación de los grupos paramilitares. 
la violación de derechos derivada de la omisión de las autoridades en proteger los derechos humanos, así como por la participación de los agentes estatales.

Igualmente, en el caso de la Masacre de Pueblo Bello vs. Colombia (2006), en el que el Estado colombiano fue declarado responsable por la violación de derechos humanos en el Pueblo Bello en el año 2006. En el caso comunidades del Jiguamiandó $y$ del Curbaradó (2005), la Corte interamericana además de la responsabilidad atribuida al Estado colombiano, impuso una medida de protección preventiva sobre las comunidades de Jiguamiandó y las familias del Curbaradó que viven a bordo del río en el departamento del Chocó, con fines de prevención de la vulneración de derechos de esa comunidad afro descendiente y las comunidades del Pueblo Indígena Kankuamo. Esta medida provisional con fines de protección, es una de las actuaciones que infiere la Corte Interamericana para presionar de una u otra manera al Estado a actuar en defensa de los derechos de las comunidades o grupos afectados.

Así las cosas, se puede apreciar que internacionalmente el Estado colombiano al igual que todos los Estados miembro de la Organización de Naciones Unidas, tienen la obligación de preservar los derechos consagrados en el cuerpo normativo de la ONU, y en caso contrario deberán ser declarados responsables administrativa e internacionalmente, por las acciones u omisiones de los agentes que actúan en representación del Estado, no sólo por la violación de tales derechos sino además por la omisión legislativa de reglamentarlos jurídicamente.

Así mismo, la acción de actos extralegales y la omisión de los agentes del Estado, conllevan a que el Estado colombiano ante los ojos de los organismos internacionales, sea catalogado como violatorio de derechos humanos, a pesar de ser un Estado Social y Democrático de Derecho - que implica que su fin primordial es la salvaguardia, protección y garantía de los derechos fundamentales de sus habitantes - y en consecuencia condenado a reparar a las victimas, como se ha visto claramente en los casos más representativos antes expuestos.

Esta situación aumenta los índices de pobreza, toda vez que las poblaciones indígenas así como todos aquellos afectados por la violencia, se ven obligados a abandonar sus tierras (desplazamiento forzado que incrementa año a año), igualmente viola gravemente los derechos fundamentales de las comunidades indígenas, pues éstas se ven obligadas en muchas ocasiones a alejarse de sus territorios ancestrales, de sus costumbres y orígenes, para tratar de encontrar un nuevo lugar en donde asentarse y preservar su cultura.

Es preciso preguntarnos en este momento: ¿Qué hace el Estado colombiano, para dar cumplimiento a lo ordenado por lo organismo Internacionales y frenar las constantes violaciones a los derechos de las poblaciones indígenas (derechos reconocidos en el ordenamiento constitucional y legal, pero no protegidos)? Como respuesta a estos interrogantes podemos afirmar que el Estado Colombiano ha creado entidades de orden nacional para brindarles apoyo en su nueva situación de vida forzada; sin embargo, esta no es una medida suficiente para la gravedad del asunto. 
El Sistema Interamericano constituye un espacio que permite observar la situación de los Derechos Humanos en América Latina, los mecanismos de protección a que acuden las víctimas y la actitud de los Estados frente a la promoción, protección y defensa de los Derechos Humanos.

Con relación al Estado las consecuencias que le acarrean la manifestación emitida por los tribunales internacionales por sus respectivos fallos, los hace de manera involuntaria evaluar la situación de vulnerabilidad de los habitantes colombianos, creándose en déficit económico si se tratase de multas y aquellas en donde se condene en crear mecanismos de protección ante la comunidad afectada.

La constante violación de los derechos consagrados en nuestra carta política, en los tratados y convenios internacionales por parte del Estado colombiano, se ha presentado por muchos años, pero es aún más preocupante que las situaciones denunciados son pocas ${ }^{17}$, motivos por los cuales hemos adquirido la connotación de ser la sociedad del silencio imperante.

Lo que sí es cierto y no hay que desconocer es que aunque no se registren demandas o más fallos en donde se condene al Estado colombiano en una situación de violación de derechos humanos, las comunidades indígenas son unos de los grupos que más ataques ha tenido por parte de individuos que actúan activa o pasivamente en nuestro Estado colombiano, que son ellos en donde debemos enfocarnos un poco más y brindarle esa protección que se merecen por tener una idiosincrasia diferente a los habitantes de nuestro país.

\section{Reflexiones Finales}

Los Organismos Internacionales, entre ellos la Organización de las Naciones Unidas, afirman insistentemente en sus informes anuales hasta el año 2009, que el Estado colombiano en forma reiterativa ha vulnerado el derecho fundamental de los pueblos indígenas a conservar su territorio ancestral.

Como consecuencia de estas situaciones fácticas, de los perjuicios causados a las poblaciones indígenas y del nexo causal que existe entre ellas, se reúnen los elementos que configuran la responsabilidad administrativa del Estado colombiano por ser este el único responsable de brindar los mecanismos necesarios para salvaguardar el derecho al territorio ancestral de las comunidades indígenas.

Así mismo actualmente se presentan dos situaciones concretas que nos permiten vincular de manera directa al Estado como responsable de este tipo de vulneraciones, las cuales son la Consulta Previa y la Omisión Legislativa. La ausencia de Consulta Previa, elevada al rango de derecho fundamental para las poblaciones indígenas, genera responsabilidad del Estado colombiano, primero cuando es desconocida por

17 No se denuncia bien sea por miedo de las víctimas, por no ser temas de interés para los medios de Comunicación o por proteger intereses del Estado Colombiano. 
el Estado al no ser realizada como requisito para intervenir un territorio ancestral indígena, omisión que pone de presente un ejercicio arbitrario del poder del Estado sin observar los principios legicentristas que deben guiar la actuación administrativa del Estado Social de Derecho, y segundo cuando el Estado practica la Consulta Previa para cumplir con el requisito, pero las apreciaciones de la comunidad indígena no se tienen en cuenta por parte de la administración.

La Omisión legislativa, se pone en evidencia al confirmarse que mediante los procedimientos adecuados, el legislativo no ha expedido la Ley Orgánica de Ordenamiento Territorial (LOOT), a pesar de ser un mandato constitucional próximo a cumplir 20 años, configurándose así la falta de reglamentación de los derechos territoriales de las poblaciones indígenas, como principio fundamental de su autonomía.

Visto lo anterior, se plantea la posibilidad jurídica de acudir a la Corte Interamericana para que sea ésta quien declare la responsabilidad internacional del Estado Colombiano, por ausencia de consulta previa, por no reconocer el carácter imperativo de las comunidades indígenas sobre sus territorios ancestrales, y por omisión legislativa.

\section{REFERENCIAS}

Anaya, J. (2004). Informe del Relator Especial de la Organización de Naciones Unidas.

Boletín de la Sociedad Geográfica Colombiana: "Ley de ordenamiento territorial. Bases para la nueva organización de Colombia. No. 134. Bogotá, agosto de 2002.

Cancado, A; Ventura, M. (2003). El futuro de la Corte Interamericana. San José, Costa Rica. Corte i.d.h.

Centro Independiente de Noticias (2008). Recuperado el día 11 de noviembre de 2009 del sitio Web http://cinoticias.com/tag/etnocidio/.

Comisión Interamericana de Derechos Humanos (1999). Tercer informe sobre la situación de los derechos humanos en Colombia.

Constitución Política de Colombia de 1991.

Cruz, J.; Rodríguez, A. (1999). Revista del Ministerio de Trabajo e Inmigración. Universidad de la Rioja. Recuperado del día 15 de marzo de 2010 del sitio Web www. dialnet.unirioja.es/servlet/articulo?codigo.

Departamento Nacional de Estadística (2005). Recuperado el día 15 de febrero 2010 de la sitio Web http://www.dane.gov.co/censo/.

Díaz, H. (1999). Autonomía Regional. La Autodeterminación de los Pueblos Indios. (Tercera Edición) México D.F.: Siglo XXI Editores.

Fajardo, L. y Otros (1999). Manuel Quintín Lame y los guerreros de Juan Tama multiculturalismo, magia y resistencia. Bogotá: Nossa y Jara Editores. 
Fondo de las Naciones Unidas para la Infancia (2009). Los Pueblos Indígenas en Colombia.

Derechos Políticas y Desafíos. Bogotá Colombia.

Herreño, A. El Otro Derecho (2004). Estado colombiano Evolución Política y Legal del Concepto del Territorio Ancestral Indígena en Colombia. Bogotá D.C., Colombia: ILSA

Jaramillo, E. (2003). Territorio, Los pueblos indígenas y el conflicto colombiano. Identidad Étnica y Estado. Revista Asuntos Indígenas No. 4. Copenhague, Grupo Internacional de Trabajo sobre Asuntos Indígenas IWGIA.

Muyuy, G. (1998). Indígenas Colombianos y su Relación con el Estado Colombiano. Memorias 49 Congreso Internacional de Americanistas en homenaje a Monseñor Leonidas Proaño. Quito.

Organización Nacional Indígena de Colombia ONIC (1995). Tierra Profanada. Grandes proyectos en territorios indígenas de Colombia, Bogotá: Disloque Editores.

Organización Nacional Indígena de Colombia ONIC (2008). Crisis humanitaria y DDHH en los pueblos indígenas, recuperado el día 25 de febrero de 2010 del sitio Web http://movimientos.org/enlacei/show_text.php3?key=13523.

Organización de Naciones Unidas. (2007). Informe del Alto Comisionado para los Derechos Humanos.

Organización de Naciones Unidas. (2009). Informe del Alto Comisionado para los Derechos Humanos.

Provea, (1997). Derecho a la tierra. Todos los Derechos para Todos. Informe Anual. Caracas.

Rodríguez, G. (2005). Comunidades Étnicas en Colombia. Universidad del Rosario.

\section{Legislación}

Convenio 169 de la Organización Internacional del Trabajo (OIT) de las Naciones Unidas.

Decreto 2164 de 1995. Diario Oficial No 42.140, del 7 de diciembre de 1995.

Decreto 250 de 2005.

Jurisprudencia

Corte Constitucional

Sentencia C- 574 de 1992, Magistrado Ponente Ciro Angarita Barón.

Sentencia T-443 de 1993, Magistrado Ponente Antonio Barrera Carbonell.

Sentencia T-188 de 1993, Magistrado Ponente Eduardo Cifuentes Muñoz.

Sentencia T-342 de 1994, Magistrado Ponente Antonio Barrera Carbonell. 
Sentencia T-007 de 1995, Magistrado Ponente Antonio Barrera Carbonell.

Sentencia T-672 de 1996, Magistrado Ponente Alejandro Martínez Caballero.

Sentencia SU- 039 de 1997, Magistrado Ponente Antonio Barrera Carbonell.

Sentencia T-652 de 1998, Magistrado Ponente Carlos Gaviria Díaz.

Sentencia T-634 de 1999

\section{Sitios Web}

http://www.acnur.org/biblioteca/pdf/4885.pdf

http://www.dane.gov.co/censo/.

http://www.dane.gov.co/files/censo2005/etnia/sys/etnias.pdf

http://www.cidh.org/countryrep/colom99sp/capitulo-10.htm

http://www.oas.org/Juridico/spanish/tratados/b-32.html

http://www.acnur.org/biblioteca/pdf/4885.pdf

ht t p://ww w.hchr.org.co/documentoseinformes/documentos/ relatoresespeciales/2010/relatores.php3?cod $=1 \&$ cat $=82$

http://www.nacionesunidas.org.co/index.shtml?apc=BB--18-- \&x=59010

http://www.scribd.com/Informe-Relator-ONU-Principios-sobre-Consulta-aPueblos-Indigenas-Abril-2009/d/1461220

http://www.cinep.org.co/node/648

www.etniasdecolombia.org

http://www.oas.org/Juridico/spanish/tratados/b-32.html )

dialnet.unirioja.es/servlet/articulo?codigo

http://movimientos.org/enlacei/show_text.php3?key=13523 